\title{
Changes in contents of polyacetylenes and carotenoids in carrots kept at different temperatures after harvest
}

\author{
T. Ahmad ${ }^{1}$, S. Binger ${ }^{2}$ and K. Brandt ${ }^{2}$ \\ ${ }^{1}$ Institute of Horticultural Sciences, University of Agriculture, Faisalabad-38040, Pakistan and ${ }^{2}$ Human Nutrition Research \\ Centre, School of Agriculture, Food and Rural Development, Newcastle University, Agriculture Building, Newcastle upon \\ Tyne, NE1 7RU, UK
}

Polyacetylenes and carotenoids are bioactive compounds most likely responsible for a range of health promoting properties of carrots ${ }^{(1)}$. When carrots were stored according to industrial best practice at $1^{\circ} \mathrm{C}$, no loss of bioactive compounds was detected even after 4 months of storage ${ }^{(2)}$. However, at later stages of the supply chain, carrots may be exposed to higher temperatures than $1^{\circ} \mathrm{C}$, this can occur during transport, display in shops and in particular after purchase by the consumer. The objective of the present work was to determine how higher temperatures may affect the contents of these compounds during the stages before the product quality deteriorates visibly, in order to improve the advice to retailers and consumers.

Carrots of the Nantes-type $\mathrm{F}_{1}$ Hybrid Oranza were harvested from the field, washed, packaged in plastic bags and stored at $4.5^{\circ} \mathrm{C}$ for up to $60 \mathrm{~d}$ or at $20^{\circ} \mathrm{C}$ for up to $12 \mathrm{~d}$. Samples were taken at regular intervals, freeze-dried and extracted with ethyl acetate, to determine the contents of polyacetylenes and carotenoids by HPLC, using a water-methanol-ethyl acetate gradient. Three polyacetylenes (falcarindiol, falcarindiol-3-acetate and falcarinol) and carotenoids (lutein, alpha-carotene and beta-carotene) were detected at 205 and $450 \mathrm{~nm}$, respectively and quantified using authentic standards.

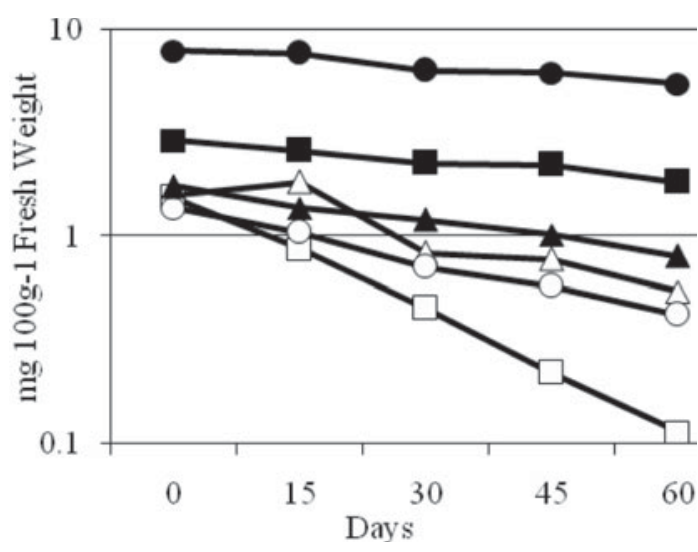

Fig. 1. Changes at $4 \cdot 5^{\circ} \mathrm{C}$.

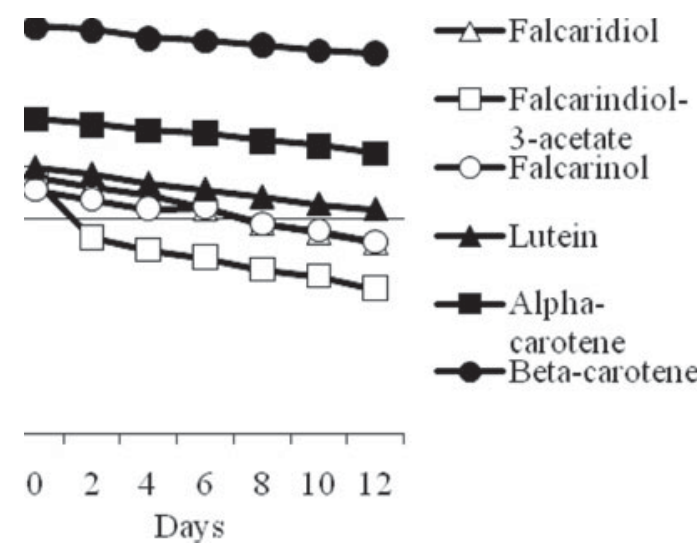

Fig. 2. Changes at $20^{\circ} \mathrm{C}$.

Contents of both polyacetylenes and carotenoids were reduced exponentially $\left(R^{2}>0.8\right.$ for all compounds and temperatures) and significantly $(P<0.01$ for all $)$ during the experimental periods. At $4.5^{\circ} \mathrm{C}$, average rates of reduction were $2.3 \%$ day ${ }^{1}$ for polyacetylenes and $0.7 \%$ day $^{(1)}$ for carotenes, at $20^{\circ} \mathrm{C}$ they were $8.8 \%$ day $^{(1)}$ for polyacetylenes and $2.5 \%$ day ${ }^{(1)}$ for carotenes. More than half of the polyacetylenes were lost after $12 \mathrm{~d}$ at $20^{\circ} \mathrm{C}$ or $30 \mathrm{~d}$ at $4.5^{\circ} \mathrm{C}$, with almost one third of the carotenoids after $12 \mathrm{~d}$ at $20^{\circ} \mathrm{C}$ or $45 \mathrm{~d}$ at $4.5^{\circ} \mathrm{C}$.

It can be concluded that at these temperatures both polyacetylenes and carotenoids are reduced already during short-term storage, enough to cause a substantial loss of nutritional value, even if the carrots still look fresh.

This work was supported by Higher Education Commission of Pakistan under the scheme 'International Research Support Initiative Programme'.

1. Brandt K, Christensen LP, Hansen MJ et al. (2004) Trends Food Sci Technol 15, 384-389.

2. Kidmose U, Hansen SL, Christensen LP et al. (2004) J Food Sci 69, 388-394. 